\title{
Perancangan Kendali Manuver Untuk Menghindari Tabrakan Pada Kapal Patroli Cepat Berbasis Pengujian Model
}

\author{
Kusnindar Priohutomo ${ }^{l * *}$, A.A. Masroeri ${ }^{2)}$, Chandra Permana ${ }^{l)}$ \\ ${ }^{1)}$ Balai Teknologi Hidrodinamika, Badan Pengkajian dan Penerapan Teknologi \\ Jl. Hidrodinamika, Kompleks ITS, Surabaya, Indonesia, 60112 \\ ${ }^{2)}$ Departemen Teknik Sistem Perkapalan, Fakultas Teknologi Kelautan, ITS, Surabaya, Indonesia, 60112
}

diajukan pada :08/08/17 direvisi pada $: 13 / 10 / 17 \quad$ diterima pada $: 26 / 10 / 17$

\begin{abstract}
Abstrak
Kendali manuver kapal untuk menghindari tabrakan menjadi masalah penting pada sebagian besar sistem transportasi kapal. Banyak kajian yang dilakukan agar kapal dapat terhindar dari tabrakan. Tetapi semuanya menggunakan pendekatan numerik. Pendekatan numerik memiliki kelemahan yaitu nilai yang diperoleh adalah nilai hampiran dan bukan nilai exact. Oleh karena itu perlu dilakukan kajian kendali manuver kapal menggunakan pendekatan pengujian skala model. Pada paper ini akan dibahas perancangan kendali manuver yang akan digunakan pada model kapal untuk menghindarkan kapal dari tabrakan. Dimana didalam sistem kendali tersebut terdapat beberapa sensor, antara lain sensor ultrasonic, sensor gyro dan kamera Qualysis. Pengujian dilakukan di kolam Manuvering Ocean Basin milik Balai Teknologi Hidrodinamika (d/h LHI), BPP. Teknologi. Model kapal yang digunakan adalah kapal patroli cepat (fast patrol boat). Halangan yang dipasang berjumlah 1 dan dalam posisi diam. Dari pengujian model kapal yang dilakukan, perancangan kendali manuver terbukti mampu menghindarkan kapal dari terjadinya tabrakan. Jarak minimum kapal dan halangan pada jarak tabrakan $250 \mathrm{~m}$ sebesar 88,25 m, pada jarak tabrakan $200 \mathrm{~m}$ sebesar 47,33 m sedangkan pada jarak tabrakan $150 \mathrm{~m}$ sebesar $12,75 \mathrm{~m}$.
\end{abstract}

Copyright $\odot$ 2017, KAPAL, 1829-8370 (p), 2301-9069(e)

Kata Kunci : kendali manuver, menghindari tabrakan, kapal patroli cepat,, jarak tabrakan

\section{PENDAHULAN}

Menghindari tabrakan menjadi masalah penting pada sebagian besar sistem transportasi kapal. Tujuan dari manuver anti tabrakan adalah agar kapal terhindar dari resiko tabrakan dan menentukan tindakan untuk menghindari atau mengurangi tabrakan [1].

Banyak penelitian tentang perancangan kendali untuk menghindari tabrakan pada kapal dengan berbagai metode. Metode yang pernah digunakan antara lain, metode perhitungan manual, metode $\mathrm{H}$ autopilot, metode logika fuzzy dan neurofuzzy [2]. Setiap metode memiliki kelebihan dan kekurangan yang berbeda. Metode

*) Penulis Korespondensi :

Email : kusnindar.priohutomo@gmail.com numerik memiliki kekurangan yaitu nilai yang dihasilkan merupakan nilai hampiran dan bukan nilai exact.Beberapa kajian yang terkait dengan menghindari tabrakan kapal antara lain:

[3] Kajian tentang "Perancangan Sistem Kontrol Berbasis Logika Fuzzy Pada Kapal Niaga Untuk Menghindari Benda Asing Di Perairan Tanjung Perak". Benda asing ini dimaksud adalah jaring-jaring ikan, batu karang dan kapal nelayan. Setpoint sistem pengendalian ini adalah lintasan (jarak antara benda asing dengan posisi kapal yang diharapkan). Objek yang digunakan pada penelitian ini adalah kapal niaga. Tipe logika fuzzy yang digunakan adalah fuzzy Sugeno dengan masukan error yaw (e) dan yaw rate (r). Keluaran fuzzy adalah sinyal command rudder $(\delta c)$. Dari hasil penelitian ini menyatakan, bahwa: (a) 
Masukan fuzzy berupa error yaw (e) dan yaw rat (r). Masing-masing masukan memiliki 7 fungsi keanggotaan. Sedangkan keluaran fuzzy berupa sinyal command rudder $(\delta)$ dengan 7 fungsi keanggotaan. Error yaw memiliki rentang data antara -35 sampai 35. Yaw rate memiliki rentang 7 sampai 7. Untuk fungsi keanggotaan keluaran fuzzy, merupakan nilai tunggal yaitu $\mathrm{NB}=-3$, $\mathrm{NM}=-2, \mathrm{NS}=-1, \mathrm{Z}=0, \mathrm{PS}=1, \mathrm{PM}=2, \mathrm{~PB}=3$. (b) Diperoleh waktu kestabilan pada pengujian sistem pengendalian pada setpoint konstan, yaitu untuk mencapai $\mathrm{k}$ estabilan pada sudut $27.5 \mathrm{deg}$ diperlukan waktu sekitar 470 detik. (c) Pengujian sistem pengendalian dengan setpoint lintasan, menunjukkan respon terbaik pada pengujian 1 dengan error steady state minimal mencapai angka $0.34 \%$. Sedangkan pada pengujian 2 error steady state minimal mencapai angka $6.1 \%$

[4] Kajian tentang "Perancangan Sistem Kontrol Logika Fuzzy Pada Manuver Nonlinier Kapal Perang Kelas Sigma”. Dari penelitian yang dilakukan dapat diambil kesimpulan bahwa pada pengujian open loop, respon yang dihasilkan masih belum stabli dan menanjak menuju tak hingga baik pada saat uji turning step $20^{\circ}$ dan 30

${ }^{0}$. Hal ini dikarenakan sistem open loop merpakan persamaan orde tinggi sehingga respon sistem sangat cepat dan tidak terkendali. Pada pengujian close loop dengan turning step $20^{\circ}$ tanpa gangguan diperoleh maksimum overshoot sebesar 5,30, settling time 100 detik, rise time sebesar 11 detik dan peak time sebesar 25,3 detik. Pada uji turning step $30^{\circ}$ diperoleh maksimum overshoot sebesar $6,4^{\circ}$, settling time 104,5 detik, rise time sebesar 7,3 detik dan peak time sebesar 30 detik. Pada pengujian close loop dengan turning step $20^{\circ}$ dengan gangguan diperoleh maksimum overshoot sebesar $5,16^{\circ}$, settling time 90,3 detik, rise time sebesar 10,35 detik dan peak time sebesar 26,2 detik. Pada uji turning step $30^{\circ}$ diperoleh maksimum overshoot sebesar $6,7^{\circ}$, settling time 98,3 detik, rise time sebesar 13,2 detik dan peak time sebesar 68,4 detik. Error tracking pada pengujian close loop tanpa halangan diam sebesar 0,016 meter tanpa gangguan dan 0,0156 meter dengan gangguan. Sedangkan error tracking dengan halangan diam sebesar 23,15 meter tanpa gangguan dan 23,19 meter dengan gangguan. Performansi manuver telah sesuai dengan standard IMO dengan advance diameter sebesar 154,33 meter atau sebesar 1,45 dan jarak tactical diameter sebesar 182,8 meter atau sebesar 1,72 . Untuk penelitian berikutnya, dapat dilakukan perancangan dengan menggunakan mode kontrol yang lebih kompleks antara lain fuzzy sliding mode kontrol dengan halangan dan gangguan yang bervariasi.
[5] Kajian tentang "Perancangan Sistem Kendali Kapal Untuk Menghindari Tabrakan Menggunakan Pengolahan Citra". Kesimpulan dari penelitian ini adalah: (a). Berdasarkan hasil pengujian keseluruhan sistem, kapal berhasil menghindari objek pada semua skenario. (b) Sistem bekerja optimal ketika objek diam, hal ini dipengaruhi oleh kemampuan pemrosesan SBC untuk mengidentifikasi objek dan gangguan pada kamera berupa distorsi lensa pada kedua sisi kamera. (c) Dengan menggunakan pengolahan citra untuk mengindetifikasi jarak objek diketahui bahwa sudut optimal pembacaan objek adalah pada rentang $75^{\circ}$ sampai dengan $105^{\circ}$. Pada pembacaan koordinat objek didapatkan nilai ratarata error pembacaan koordinat objek sebesar $0,868 \mathrm{px}$ dan nilai rata-rata error sudut pembacaan objek 7,45 \%cm. (d) Logika Fuzzy digunakan untuk menentukan besar sudut putar motor servo. Nilai error hasil perbandingan pengolahan mikrokontroler dengan Matlab sebesar $0^{\circ}$ sampai $5,61^{\circ}$. Sudut putar maksimum motor servo adalah $\pm 45^{\circ}$ dari keadaan lurus $\left(90^{\circ}\right)$. Besar sudut ini juga dipengaruhi oleh keterbatasan perputaran rudder.

Dari beberapa literatur maka dilakukan penelitian dengan metode pengujian kapal skala model di kolam pengujian manuver. Untuk keperluan pengujian tersebut diperlukan perancangan kendali manuver yang tepat agar kapal dapat terhindar dari tabrakan. Penggunaan mikrokontoller dan beberapa sensor antara lain sensor jarak (ultrasonic) untuk mendeteksi jarak kapal dengan halangan, sensor gyro untuk mengetahui pergerakan yaw kapal, servo rudder untuk mengetahui pergerakan rudder kapal dan kamera Qualysis untuk mengetahui jarak antara kapal dengan halangan.

\section{METODE}

Metodologi penelitian dikembangkan untuk menghasilkan rancangan kendali manuver yang baik secara teknis, dimana langkah-langkah dalam metodologi dapat diuraikan sebagai berikut:

\subsection{Ukuran Utama Kapal}

Pertama menentukan ukuran utama kapal yang merupakan faktor penting dalam mendesain kapal. Model kapal yang digunakan mengikuti Kapal Patroli Cepat, dimana data-data ukuran utama kapal dan model yang akan digunakan dalam penelitian dapat dilihat pada Tabel 1 . 
Tabel 1. Data Utama Kapal

\begin{tabular}{clrr}
\hline No & Data Kapal & Skala Asli & Skala Model \\
\hline 1 & LOA & $90,00 \mathrm{~m}$ & $1,27 \mathrm{~m}$ \\
2 & LWL & $86,45 \mathrm{~m}$ & $1,22 \mathrm{~m}$ \\
3 & Breadth & $13,00 \mathrm{~m}$ & $0,185 \mathrm{~m}$ \\
4 & Draught & $3,60 \mathrm{~m}$ & $0,051 \mathrm{~m}$ \\
5 & Displacement & $1700 \mathrm{Ton}$ & $4,66 \mathrm{~kg}$ \\
6 & LCB & \multicolumn{2}{c}{$54 \% \mathrm{LPP}$} \\
7 & Service Speed & $18 \mathrm{Knot}$ & $1,1 \mathrm{~m} / \mathrm{s}$ \\
8 & Top Speed & $28 \mathrm{Knot}$ & $1,711 \mathrm{~m} / \mathrm{s}$ \\
9 & Propeller & $3,30 \mathrm{~m}$ & $0,047 \mathrm{~m}$ \\
\hline
\end{tabular}

\subsection{Peralatan Sistem Kontrol Collision}

\section{Avoidance}

\subsubsection{Mikrokontoler Arduino Mega 2560}

Arduino Mega 2560 adalah papan mikrokontroler berdasarkan Atmega 328. Papan ini memiliki 54 digital input/output pin (14 pin dapat digunakan sebagai output PWM), 16 input analog. $16 \mathrm{MKz}$ osilator kristal, USB koneksi, Jack listrik, header ICSP dan tombol reset. Dengan menghubungkannya ke komputer melalui kabel USB atau power dihubungkan dengan adaptor AC-DC atau baterai untuk mengaktifkan. Arduino Mega2560 adalah versi terbaru yang menggantikan versi Arduino Mega. Gambar mikrokontroller arduino ditunjukkan pada Gambar 1.

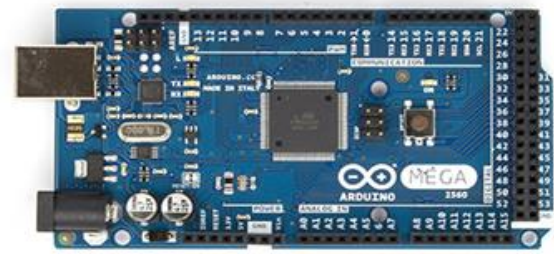

Gambar 1. Mikrokontroller Arduino Mega 2560

\subsubsection{Sensor Ultrasonic}

Sensor ultrasonic yang digunakan merupakan modul pengukur jarak non kontak. Untuk memicu dan membaca data pengukuran hanya memerlukan 1 buah pin mikrokontroler. Selain itu disediakan antarmuka komunikasi 12C. Untuk mengaktifkan sensor maka modul diberi triger pulsa maka sensor akan mengeluarkan sinyal $P W M$ dan duty cycle tersebut sebagai jarak objek dengan sensor. Selanjutnya data ultrasonik dikirim ke mikrokontroler dengan komunikasi serial. Data yang dikirim adalah data 8-bit dengan nilai 5-255 dimana nilai 0 digunakan sebagai tanda akhir data. Gambar sensor ultrasonic ditunjukkan pada Gambar 2.

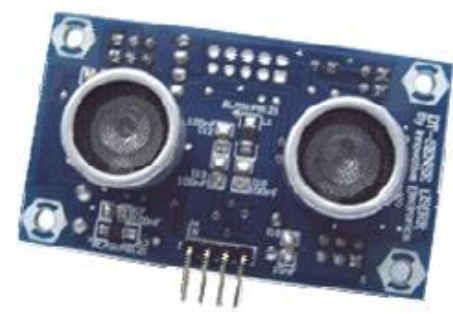

Gambar 2. Sensor Ultrasonic

\subsubsection{Sensor IMU}

Sensor IMU (inertial measurements unit) merupakan sebuah komponen inersia yang digunakan untuk panduan sebuah sistem yang umumnya digunakan pada kendaraan darat, kendaraan laut, dan roket kendali. Sensor IMU bekerja dengan mensensing sebuah gerakan, dan perpindahan arah dengan menggunakan kombinasi sensor accelerometer digunakan untuk menentukan percepatan gravitasi, gyroscopes digunakan untuk menentukan percepatan sudut dan sensor magnetometer digunakan untuk heading atau menentukan arah mata angin dan digunakan sebagai refrensi pada sumbu yaw.

Sensor $I M U$ yang digunakan adalah sensor Gyro dengan tipe GY - 521 yang ditunjukkan pada Gambar 3.

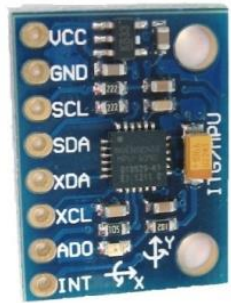

Gambar 3. Sensor IMU GY - 521

\subsubsection{Radio Telemetry}

Radio telemetry adalah perangkat keras yang berfungsi untuk mentransmisikan sebuah data dengan menggunakan sistem komunikasi wireless. Radio telemetry yang digunakan adalah tipe $3 \mathrm{DR}$ radio telemetry, dimana radio telemetry ini memiliki beberapa fitur diantaranya adalah memiliki transmit power up to $20 \mathrm{dBm}$ dengan maximum output power mencapai $100 \mathrm{~mW}$, memiliki sensitifitas $-117 \mathrm{dBm}$, membutuhkan tegangan yang mencapai 3,7 - $6 V D C$, memiliki frekuensi $433 \mathrm{Mhz}$ yang digambarkan pada Gambar 4. 


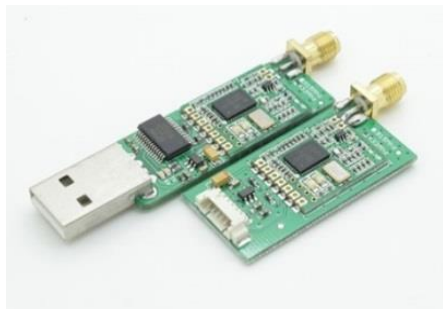

Gambar 4. Radio Telemetry $433 \mathrm{Mhz}$

\subsection{Perancangan Kontrol Kemudi}

\subsubsection{Perancangan Sensor Ultrasonic Model} Uji

Pada manual book sensor ultrasonic Elecfreaks [6], perancangan sensor ultrasonic berfungsi untuk mengetahui dan mengukur jarak model dengan halangan. Rangkaian block diagram sensor ultrasonic digambarkan pada Gambar 5.

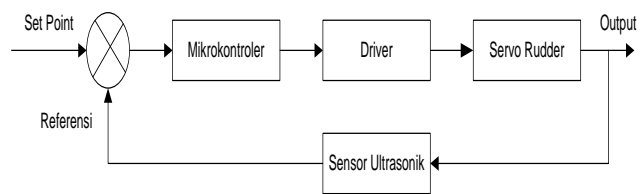

Gambar 5. Rangkaian Block Diagram Sensor Ultrasonic

Perancangan sensor ultrasonic tersebut menggunakan komunikasi wire dengan menghubungkan $V c c$, Gnd, Echo dan trigger pin. Adapun perancangan sensor ultrasonic dapat dilihat pada gambar 6

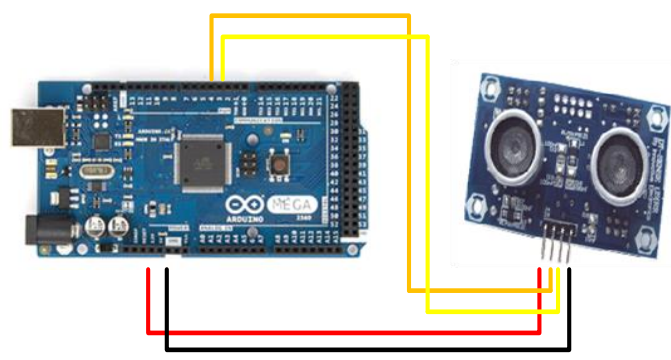

Gambar 6. Perancangan Sensor Ultrasonic

Untuk menghindari kapal dari tabrakan, maka sensor ultrasonic di setting seperti pada Tabel 2.

Tabel 2. Setting Sensor Ultrasonic

\begin{tabular}{ccc}
\hline No & Jarak Tabrakan $(\mathbf{m})$ & Setting Sensor $(\mathbf{m})$ \\
\hline 1 & 250 & 285 \\
2 & 200 & 235 \\
3 & 150 & 185 \\
\hline
\end{tabular}

\subsubsection{Perancangan Sensor Gyro Model Uji}

Menurut manual book dari Gyro and Acceleration Sensor [7], perancangan sensor gyro berfungsi untuk mengetahui dan mengukur perubahan sudut heading yaw model kapal.
Rangkaian block diagram sensor gyro dapat digambarkan digambarkan pada Gambar 7.

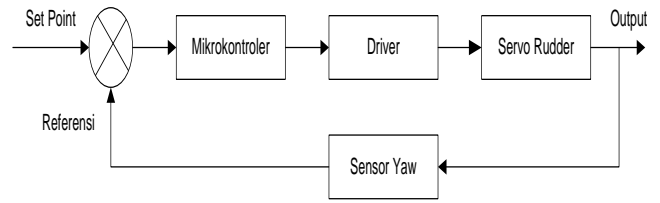

Gambar 7. Rangkaian Block Diagram Sensor Yaw

Perancangan sensor gyro tersebut menggunakan komunikasi data serial berupa i2c dengan menghubungkan $\mathrm{Vcc}$, Gnd, SDA, SCl dan INT. Adapun perancangan sensor gyro dapat dilihat pada Gambar 8.

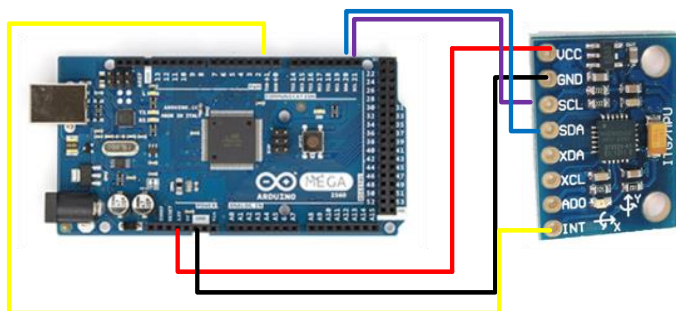

Gambar 8. Perancangan Sensor Yaw

\subsubsection{Perancangan Servo Rudder Model Uji}

Perancangan servo rudder berfungsi untuk mengetahui dan mengukur perubahan sudut rudder model kapal. Rangkaian block diagram servo rudder digambarkan pada Gambar 9.

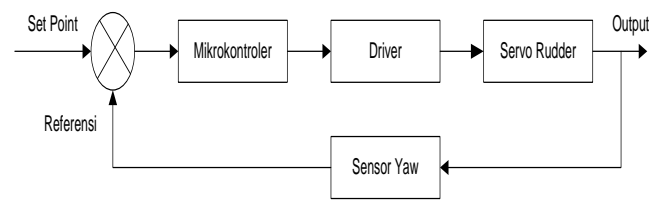

Gambar 9. Rangkaian Block Diagram Servo Rudder

Perancangan servo rudder dengan menggunakan metode PWM (Pulse Width Modulation). Dengan metode $P W M$ dapat dihasilkan gerakan servo yang cukup akurat dengan resolusi yang diinginkan. Adapun perancangan servo rudder dapat dilihat pada Gambar 10.

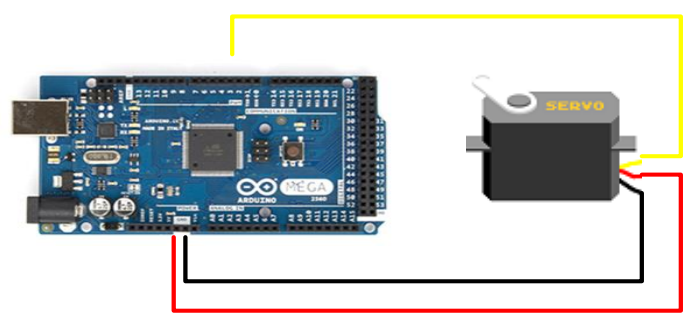

Gambar 10. Perancangan Servo Rudder 


\subsubsection{Perancangan Radio Telemetry Model Uji}

Pada manual book Advanced Telemetry System [8], perancangan radio telemetry pada model uji berfungsi untuk mentransmisikan informasi raw data perubahan yaw model kapal kepada sistem ground station dengan secara realtime. Perancangan radio telemetry pada modle kapal dengan menggunakan 2 komunikasi data serial Rx (receiver) dan Tx (transmitter). Adapun perancangan radio telemetry yang dapat ditunjukkan pada Gambar 11.

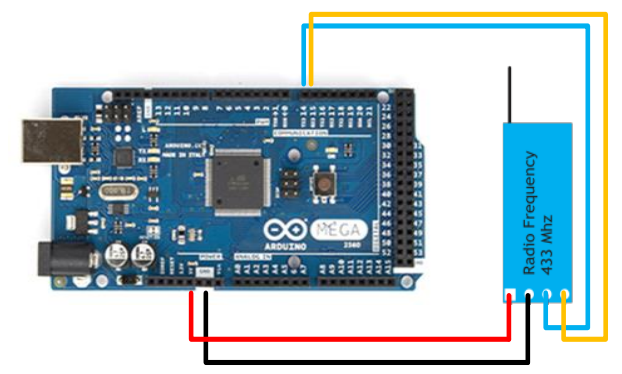

Gambar 11. Perancangan Radio Telemetry

\subsection{Sistem Pengukuran Trajectory Model}

Pengukuran pergerakan trajectory model selama pengujian dilakukan menggunakan peralatan QTM (Qualysis Track Manager). QTM adalah sebuah perangkat lunak yang dirancang dengan menggunakan model kamera Qualisys, kamera tersebut digunakan sebagai media pengumpulan data yang cepat dan tepat. Sistem ini memungkinkan pengguna untuk merekam data secara real time baik dalam $2 \mathrm{D}, 3 \mathrm{D}$ dan $6 \mathrm{DOF}$ dengan respon waktu yang cepat [9]. QTM juga dapat melakukan identifikasi marker secara otomatis baik passive maupun aktif marker, mudah dalam penambahan kamera jika diperlukan perluasan objek area yang direkam.

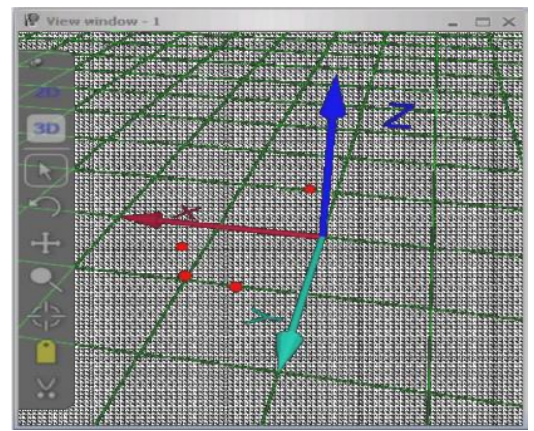

Gambar 12. Tampilan sumbu pada $Q T M$

Pada saat capture pengukuran dilaksanakan software akan segera merekam pergerakan marker (jika tidak ada setting delay) dan dapat ditampilkan preview dari pengukuran dengan tombol preview. Untuk sampling rate dari pengukuran sendiri bisa diatur dari capture periodenya. Hasil dari kalibrasi QTM dapat dilihat pada Gambar 12. Dimana titik merah merupakan marker kapal yang telah dipasang marker Qualisys, sedangkan sumbu $\mathrm{x}$, y dan $\mathrm{z}$ masingmasing mewakili sumbu yang ada di kolam pengujian.

\subsection{Skenario Pengujian}

Skenario pengujian pada penelitian ini mengikuti pattern dari COLREG 72 [10]. COLREG 72 telah mengatur skenario untuk menghindari tabrakan sesuai dengan posisi kapal, antara lain posisi head-on (kapal berhadapan), posisi crossing (kapal berpotongan) dan overtaking (kapal dibelakang akan mendahului kapal didepannya). Dari ketiga skenario menurut COLREG 72 yang akan digunakan pada penelitian ini adalah skenario head-on (kapal berhadapan). Dimana kedua kapal akan melakukan pergerkan kemudi (rudder) ke arah starboard (kanan). Sehingga kapal terhindar dari tabrakan.

Pada penelitian ini kecepatan kapal dibuat konstan pada kecepatan 10 knot. Sedangkan halangan dalam posisi diam. Pengujian dilakukan di Kolam MOB milik BTH (d/h LHI), BPP.Teknologi pada kondisi air tenang (non disturbance).

Variasi yang dilakukan adalah variasi jarak kapal terhadap halangan (jarak tabrakan) yaitu 250 meter, 200 meter dan 150 meter. Pengujian pada setiap variasi jarak kapal terhadap halangan dilakukan sebanyak $3 \mathrm{x}$ agar dapat diambil ratarata.

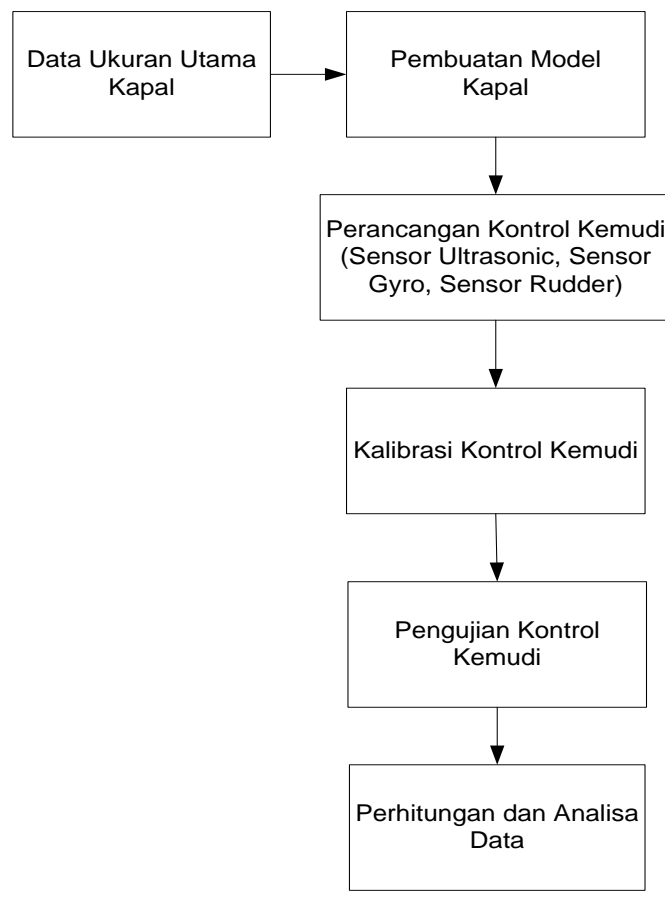

Gambar 13. Flowchart Pengujian 


\section{HASIL DAN PEMBAHASAN}

\subsection{Trajectory Kapal}

\subsubsection{Trajectory Kapal Pada Jarak Tabrakan} $250 \mathrm{~m}$

Dari hasil pengujian dengan menggunakan kamera Qualysis didapatkan grafik trajectory kapal (sumbu x, sumbu y) pada jarak tabrakan 250 m, ditampilkan pada Gambar 14.

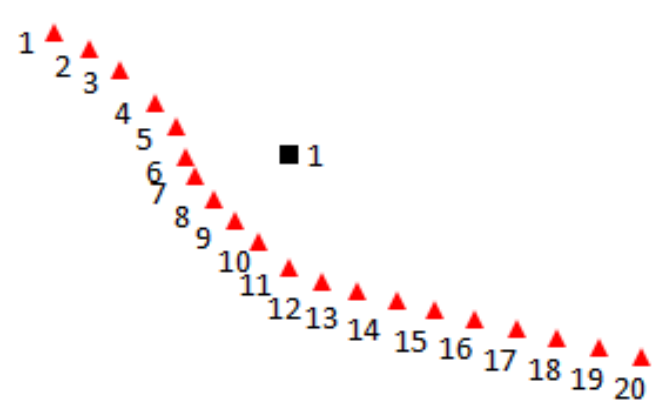

Gambar 14. Trajectory Kapal dan Halangan Pada Jarak Tabrakan $250 \mathrm{~m}$

Dari Gambar 14 terlihat bahwa pada jarak tabrakan $250 \mathrm{~m}$ kapal masih dapat menghindari halangan.

\subsubsection{Trajectory Kapal Pada Jarak Tabrakan $200 \mathrm{~m}$}

Dari hasil pengujian dengan menggunakan kamera Qualysis didapatkan grafik trajectory kapal (sumbu x, sumbu y) pada jarak tabrakan 200 m, ditampilkan pada Gambar 15.

$$
\begin{aligned}
& { }^{1} \mathbf{A}_{3} \mathbf{A} \\
& 564 \\
& 7{ }_{8} \times 1 \\
& 10^{4} \mathrm{~A}
\end{aligned}
$$

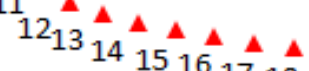

$$
\begin{aligned}
& 14{ }_{10}^{15} 16^{16}
\end{aligned}
$$

Gambar 15. Trajectory Kapal dan Halangan Pada Jarak Tabrakan $200 \mathrm{~m}$

Dari gambar 15 terlihat bahwa pada jarak tabrakan $200 \mathrm{~m}$ kapal masih dapat menghindari halangan.

\subsubsection{Trajectory Kapal Pada Jarak Tabrakan $150 \mathrm{~m}$}

Dari hasil pengujian dengan menggunakan kamera Qualysis didapatkan grafik trajectory kapal (sumbu x, sumbu y) pada jarak tabrakan 150 m, ditampilkan pada Gambar 16.

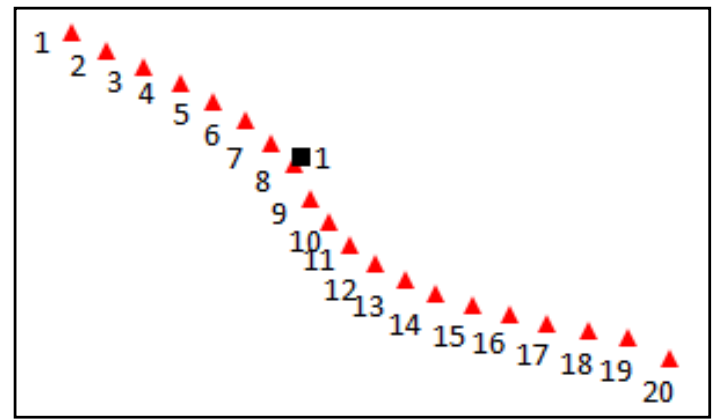

Gambar 16. Trajectory Kapal dan Halangan Pada Jarak Tabrakan $150 \mathrm{~m}$

Dari gambar 16 terlihat bahwa pada jarak tabrakan $150 \mathrm{~m}$ kapal masih dapat menghindari halangan.

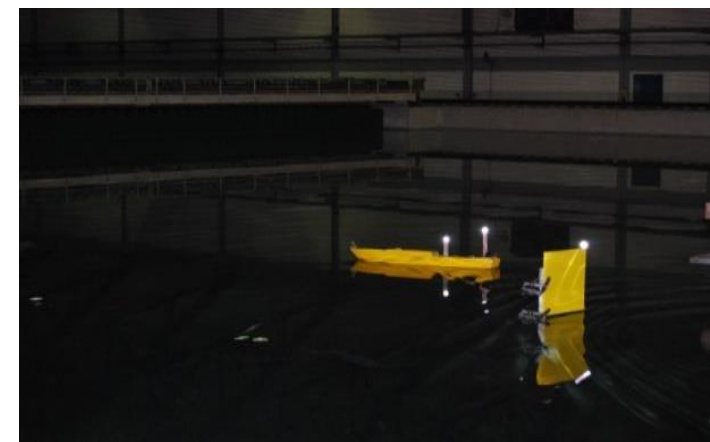

Gambar 17. Pengujian Menghindari Tabrakan

Pada Gambar 17, merupakan dokumentasi dari pengujian kendali manuver dengan jarak tabrakan $250 \mathrm{~m}$. Tampak model kapal dengan marker Qualysis disisi kanan dan kiri melewati halangan yang juga terdapat marker Qualysis.

\subsection{Jarak Kapal Terhadap Halangan}

Dari trajectory kapal dan halangan pada gambar 14, gambar 15 dan gambar 16, maka dapat dicari jarak antara kedua titik yaitu titik trajectory kapal (sumbu $\mathrm{x}$,sumbu y ) dan titik halangan (sumbu $\mathrm{x}$, sumbu y). Sumbu z pada kapal dan halangan tidak dihitung karena selama pengujian kapal bergerak pada sumbu ordinat 2D yaitu sumbu X dan Y. Adapun rumusan untuk mencari dua titik adalah sebagai berikut:

$$
\begin{gathered}
\text { Jarak }=\sqrt{(\text { Selsish } X)^{2}+(\text { Selsish } Y)^{2}} \\
\text { Jarak }=\sqrt{(X 2-X 1)^{2}+(Y 2-Y 1)^{2}}
\end{gathered}
$$


dimana $X 1=$ Nilai $X$ Halangan, $X 2=$ Nilai $X$ Kapal, $\mathrm{Y} 1=$ Nilai $\mathrm{Y}$ Halangan, $\mathrm{Y} 2=$ Nilai $\mathrm{Y}$ Kapal.

\subsubsection{Jarak Kapal Terhadap Halangan Pada Jarak Tabrakan $250 \mathrm{~m}$}

Dari Persamaan 2, maka jarak titik (sumbu x, sumbu y) trajectory kapal dan titik (sumbu $\mathrm{x}$, sumbu y) halangan pada jarak tabrakan $250 \mathrm{~m}$ dapat diketahui dan ditampilkan pada Gambar 18.

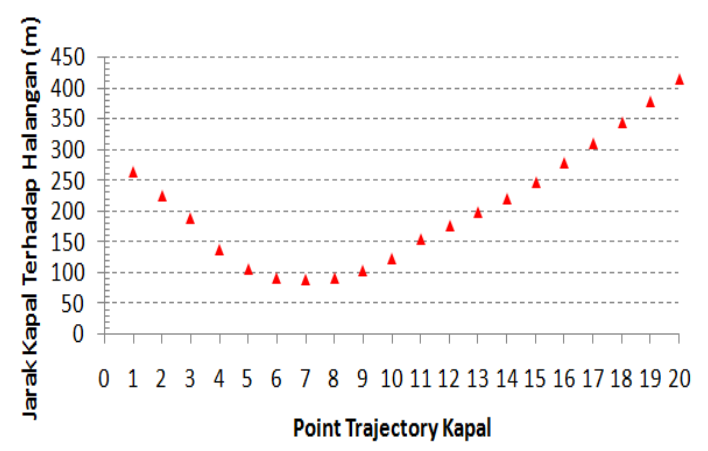

Gambar 18. Grafik Jarak Kapal Terhadap Halangan Pada Jarak Tabrakan 250 m

Pada Gambar 18, terlihat dari grafik jarak minimum kapal terhadap halangan sebesar 88.25 m pada point trajectory 7 .

\subsubsection{Jarak Kapal Terhadap Halangan Pada Jarak Tabrakan $200 \mathrm{~m}$}

Dari Persamaan 2, maka jarak titik (sumbu x, sumbu y) trajectory kapal dan titik (sumbu $\mathrm{x}$, sumbu y) halangan pada jarak tabrakan $200 \mathrm{~m}$ dapat diketahui dan ditampilkan pada Gambar 19.

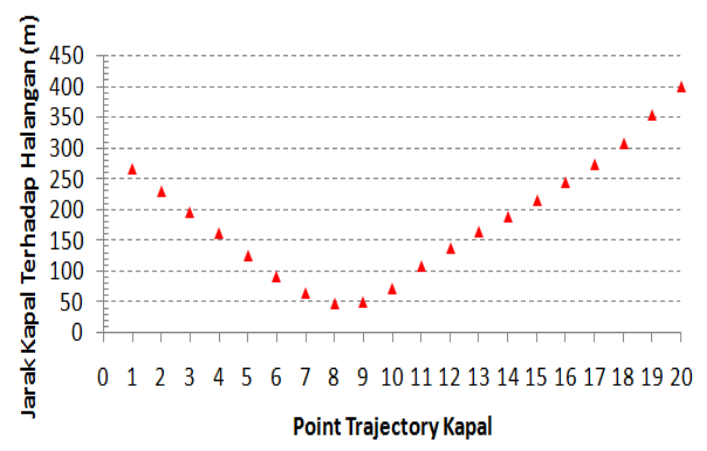

Gambar 19. Grafik Jarak Kapal Terhadap Halangan Pada Jarak Tabrakan 200 m

Pada gambar 19, terlihat dari grafik jarak minimum kapal terhadap halangan sebesar 47.33 m pada point trajectory 8 .

\subsubsection{Jarak Kapal Terhadap Halangan Pada Jarak Tabrakan 150 m}

Dari Persamaan 2, maka jarak titik (sumbu x, sumbu y) trajectory kapal dan titik (sumbu $\mathrm{x}$, sumbu y) halangan pada jarak tabrakan $150 \mathrm{~m}$ dapat diketahui dan ditampilkan pada Gambar 20.

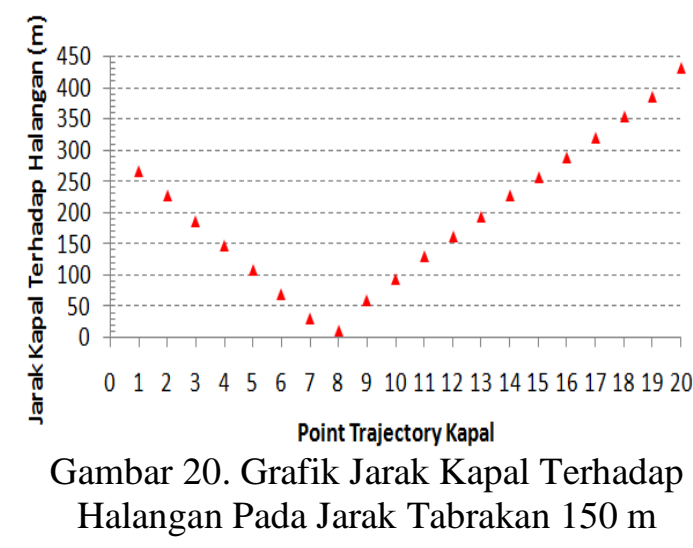

Pada Gambar 20, terlihat dari grafik jarak minimum kapal terhadap halangan sebesar 12.75 m pada point trajectory 8 .

\subsection{Pembacaan Sensor}

\subsubsection{Pembacaan Sensor Ultrasonic}

Dari setting sensor ultrasonic pada tabel 2, maka pembacaan sensor ultrasonic pada saat pengujian ditampilkan pada Tabel 3.

Tabel 3. Pembacaan Sensor Ultrsonic

\begin{tabular}{ccc}
\hline No & Jarak Tabrakan $(\mathbf{m})$ & Setting Sensor $(\mathbf{m})$ \\
\hline 1 & 250 & 276 \\
2 & 200 & 230 \\
3 & 150 & 177 \\
\hline
\end{tabular}

\subsubsection{Pembacaan Sensor Yaw}

Pembacaan sensor yaw pada saat pengujian adalah untuk mengetahui sudut heading kapal pada saat rudder sudah mencapai 30 derajat dan ditampilkan pada Tabel 4.

Tabel 4. Pembacaan Sensor Yaw

\begin{tabular}{ccc}
\hline No & Jarak Tabrakan $(\mathbf{m})$ & Setting Sensor $(\mathbf{d e g})$ \\
\hline 1 & 250 & 1,49 \\
2 & 200 & 0,97 \\
3 & 150 & 0,89 \\
\hline
\end{tabular}

\subsubsection{Pembacaan Sensor Rudder}

Pembacaan sensor rudder pada saat pengujian adalah untuk mengetahui waktu yang dibutuhkan rudder untuk mencapai 30 derajat dan ditampilkan pada Tabel 5.

Tabel 5. Pembacaan Sensor Rudder

\begin{tabular}{ccc}
\hline No & Jarak Tabrakan $(\mathbf{m})$ & Setting Sensor $(\mathbf{s})$ \\
\hline 1 & 250 & 0,3 \\
2 & 200 & 0,3 \\
3 & 150 & 0,3 \\
\hline
\end{tabular}




\subsection{Error Sensor Ultrasonic}

Dari hasil tabel 2 dan tabel 3, maka dapat dicari error sensor ultrasonic yang terjadi selama pengujian berlangsung dan ditampilkan pada Tabel 6.

Tabel 6. Error Sensor Ultrasonic

\begin{tabular}{ccccc}
\hline No & $\begin{array}{c}\text { Jarak } \\
\text { Tabrakan } \\
(\mathbf{m})\end{array}$ & $\begin{array}{c}\text { Setting } \\
\text { Sensor } \\
(\mathbf{m})\end{array}$ & $\begin{array}{c}\text { Pembacaan } \\
\text { Sensor }(\mathbf{m})\end{array}$ & $\begin{array}{c}\text { Error } \\
\text { Sensor } \\
(\mathbf{m})\end{array}$ \\
\hline 1 & 250 & 285 & 276 & 9 \\
2 & 200 & 235 & 230 & 5 \\
3 & 150 & 185 & 177 & 8 \\
\hline
\end{tabular}

\section{KESIMPULAN}

Dari hasil pengukuran dan analisa hasil pengujian maka dapat diambil suatu kesimpulan. Berdasarkan hasil percobaan didapatkan bahwa perancangan kontrol kemudi yang dipasang didalam model kapal patroli cepat selama pengujian, dapat menghindarkan kapal dari terjadinya tabrakan.

Kapal patroli cepat pada kecepatan 10 knot dapat menghindari tabrakan pada jarak $250 \mathrm{~m}$, $200 \mathrm{~m}$ dan $150 \mathrm{~m}$ pada kondisi air tenang (non disturbance). Jarak terdekat antara kapal dan halangan pada jarak tabrakan $250 \mathrm{~m}$ sebesar 88,25 m, pada jarak tabrakan $200 \mathrm{~m}$ sebesar $47,33 \mathrm{~m}$ dan pada jarak tabrakan $150 \mathrm{~m}$ sebesar $12,75 \mathrm{~m}$ pada kondisi pengujian air tenang (non disturbance). Jarak ini didapatkan pada saat kapal berada bersebelahan atau side by side dengan halangan.

Error sensor ultrasonic pada saat pengujian pada jarak $250 \mathrm{~m}$ sebesar $9 \mathrm{~m}$, pada jarak $200 \mathrm{~m}$ sebesar $5 \mathrm{~m}$ dan pada jarak $150 \mathrm{~m}$ sebesar $8 \mathrm{~m}$. Nilai error sensor ini didapatkan dari delay sensor ultrasonic itu sendiri yaitu setiap $50 \mathrm{~ms}$. Sehingga pada saat sensor melakukan looping pembacaan jarak, jarak yang diprogram terlewati dan membaca jarak terdekat selanjutnya. Sehingga ada perbedaan jarak yang diprogram dengan jarak yang ter-record.

Untuk mengatasi error sensor ultrasonic, disarankan menggunakan sensor ultrasonic yang memiliki delay lebih cepat dari $50 \mathrm{~ms}$ pengujian pada kecepatan 10 knot ke atas. Atau menggunakan sensor Lidar untuk membaca jarak kapal terhadap halangan.

\section{DAFTAR PUSTAKA}

[1] L. P. Perera, J. P. Carvalho, and C. . Guedes Soares, "Autonomous guidance and navigation based on the COLREGs rules and regulations of collision avoidance .," Adv. Sh. Des. Pollut. Prev., no. 1999, pp. 205-216, 2010.

[2] D. I. Maria, A. S. Aisjah, and A. A. Masroeri, "Perancangan Sistem Kendali Manuver Kapal Berbasis Logika Fuzzy untuk Mengatasi Faktor Gangguan Gelombang, Angin, dan Arus Laut", Jurnal Teknik Fisika ITS, pp. 1-11, 2012.

[3] A. Faruchi, A. S. Aisjah, and A. A. Masroeri, "Perancangan sistem kontrol berbasis logika fuzzy pada kapal niaga untuk menghindari benda asing di perairan tanjung perak", Jurnal Teknik Fisika ITS, pp. 1-10, 2013.

[4] D. Haris, A. S. Aisjah, and A. A. Masroeri, "Perancangan sistem kontrol logika fuzzy pada manuver nonlinier kapal perang kelas sigma ( extended ),"Jurnal Teknik POMITS, Vol. 2, No. 1, 2013.

[5] M. Iqbal, R. Nugraha, "Perancangan sistem kendali kapal untuk menghindari tabrakan menggunakan pengolahan citra", Jurnal of Engineering, Universitas Telkom, vol. 4, no. 2, pp. 1426-1433, 2017.

[6] E. Freaks, "HC-SR04 User Guide," Elec Freaks, pp. 1-6, 2011.

[7] Studuino, "Studuino Gyroscope." Environment and Software, pp. 1-15, 2012.

[8] Ats, "Advanced Telemetry Systems - Manual Tracking," pp. 1-5, 2009.

[9] A. . Fallis, "Qualisis pdf," J. Chem. Inf. Model., vol. 53, no. 9, pp. 1689-1699, 2013.

[10] IMO, “COLREGS - International Regulations for Preventing Collisions at Sea," Conv. Int. Regul. Prev. Collisions Sea, 1972, pp. 1-74, 1972. 